\title{
Long non-coding RNAs in esophageal cancer: molecular mechanisms, functions, and potential applications
}

\author{
Min Su ${ }^{1,2^{*}} \mathbb{D}$, Yuhang $\mathrm{Xiao}^{3 \dagger}$, Junliang $\mathrm{Ma}^{1 \dagger}$, Deliang Cao ${ }^{1}$, Yong Zhou ${ }^{1}$, Hui Wang ${ }^{4}$, Qianjin Liao ${ }^{2^{*}}$ \\ and Wenxiang Wang ${ }^{1 *}$
}

\begin{abstract}
Esophageal cancer (EC) is the sixth leading cause of cancer-related death worldwide. The lack of early diagnostic biomarkers and effective prognostic indicators for metastasis and recurrence has resulted in the poor prognosis of EC. In addition, the underlying molecular mechanisms of EC development have yet to be elucidated. Accumulating evidence has demonstrated that IncRNAs play a vital role in the pathological progression of EC. LncRNAs may regulate gene expression through the recruitment of histone-modifying complexes to the chromatin and through interactions with RNAs or proteins. Recent evidence has demonstrated that the dysregulation of IncRNAs plays important roles in the proliferation, metastasis, invasion, angiogenesis, apoptosis, chemoradiotherapy resistance, and stemness of EC, which suggests potential clinical implications. In this review, we highlight the emerging roles and regulatory mechanisms of IncRNAs in the context of EC and discuss their potential clinical applications as diagnostic and prognostic biomarkers.
\end{abstract}

Keywords: Long non-coding RNA, Esophageal cancer, Mechanism, Application, Biomarker

\section{Background}

Esophageal carcinoma (EC), a serious malignant cancer, is the sixth leading cause of cancer-related death [1,2]. Despite advances in multidisciplinary treatment, the 5year relative survival rate remains less than $20 \%$ [3]. EC includes the following two primary pathological types: esophageal adenocarcinoma (EAC) and esophageal squamous cell carcinoma (ESCC) [2]. EAC is the leading histological type observed in patients from western countries, whereas ESCC has become the leading cause of EC in Asian countries and predominates over EAC worldwide $[4,5]$. The pathogenesis of EC is complex and differs between EAC and ESCC. For EAC, the

\footnotetext{
*Correspondence: sumin27@126.com; liaoqianjin@hnszlyy.com; hnchw11@163.com

${ }^{\dagger}$ Yuhang Xiao and Junliang Ma contributed equally to this work. 'Department of the 2nd Department of Thoracic Surgery, Hunan Cancer Hospital and The Affiliated Cancer Hospital of Xiangya School of Medicine, Central South University, Changsha 410013, Hunan, People's Republic of China

${ }^{2}$ Department of the Central Laboratory, Hunan Cancer Hospital and The Affiliated Cancer Hospital of Xiangya School of Medicine, Central South University, Changsha 410013, Hunan, People's Republic of China Full list of author information is available at the end of the article
}

primary predisposing cause is metaplasia that is likely caused by chronic exposure to acid and bile reflux, such as in the case of Barrett's esophagus and chronic gastroesophageal reflux disease [6]. However, the origin of ESCC carcinogenesis is not fully understood. Earlystage EC can be effectively treated with curative surgery, but for advanced cases, the therapeutic strategies are limited [7]. Unfortunately, EC patients are usually diagnosed at an advanced stage accompanied with lymphatic metastasis, and therefore they are not eligible for surgical resection [8]. The current standard treatment for these patients is concurrent definitive chemoor radiotherapy, or a combination of both [9]. However, therapy resistance and tumor recurrence are major obstacles for EC therapy and are critical issues leading to poor prognoses [10]. Within the EC, a small number of cells termed cancer stem-like cells (CSCs) are considered to account for the initiation, recurrence, and therapeutic resistance of EC [10]. In recent years, compelling evidence has demonstrated the crucial roles of long non-coding RNAs (lncRNAs) in the pathogenesis and progression of EC. 
LncRNAs, which are an emerging focus of current cancer research, are defined as endogenous cellular RNAs that are more than 200 nucleotides in length and are incapable of encoding protein [11, 12]. Initially, lncRNAs were considered as transcriptional "noise," given their relatively low expression levels compared with mRNAs and their lack of protein-coding capacity [13]. However, in-depth studies in recent years revealed that lncRNAs possess certain characteristics of mRNAs; for instance, lncRNAs are transcribed by RNA polymerase II, equipped with a 3' polyA tail and a $5^{\prime}$ cap, and contain a promoter and structure consisting of multiple exons $[14,15]$. Accumulating evidence suggests that the aberrant lncRNA expression is associated with oncogenesis and the development of various cancers [16, 17]. LncRNAs have been shown to interact directly with DNA, RNA, and proteins to regulate several mechanisms, including the following: chromatin modification, RNA transcription, pre-mRNA splicing, mRNA translation, and other mechanisms that influence gene expression [18, 19]. Moreover, several lncRNAs have been functionally well-characterized in cancer pathogenesis and development and may be potential novel biomarkers for cancer diagnosis and prognosis, as well as therapeutic targets.

In this review, we focused our efforts on the recent findings regarding the molecular mechanisms and functional roles of lncRNA in EC oncogenesis and development. In addition, we discussed the potential implications of lncRNAs as biomarkers for the diagnosis and prognosis of EC.

\section{Mechanisms of IncRNAs in EC}

LncRNAs may act as signals or guides for the recruitment of chromatin-modifying complexes to induce transcription, and they may even act as decoys that bind to transcription factors (TFs) to prevent the transcription factors from binding to target gene promoter regions, thereby suppressing transcription [20, 21]. In addition, lncRNAs can hybridize to pre-mRNAs, block the recognition of splice sites by spliceosomes, and regulate the alternative splicing of pre-mRNAs to produce alternate transcripts [17, 22]. An additional biological function of lncRNAs may include serving as "miRNA sponges" through interactions with miRNAs to inactivate these small regulatory RNAs and hence increase the expression of the miRNA target genes [23-25]. Finally, lncRNAs may be involved in the modulation of protein localization, activity, and function [26]. In this section, we highlight the molecular mechanisms of lncRNAs in EC via their interactions with chromatin, DNA, RNA, and regulatory proteins (Fig. 1 and Table 1).

\section{LncRNAs localized to the chromatin}

LncRNA-dependent chromatin regulation involves the recruitment and modulation of histone-modifying enzymes that induce chromatin modification at promoters and enhancers [27, 28]. In this manner, lncRNAs can regulate gene expression through histone modification, DNA methylation, and chromatin structure alteration $[29,30]$.

It has been demonstrated that many lncRNAs are associated with polycomb repressive complex 2 (PRC2), which is responsible for the trimethylation of lysine 27 on histone 3 (H3K27me3) and mediates the silencing of the target gene through local chromatin reorganization [31]. Enhancer of zeste homolog 2 (EZH2) and SUZ12 are subunits of the PRC2 complex. Wu et al. [32] demonstrated that cancer susceptibility candidate 9 (CASC9) downregulates the expression of PDCD4 via the recruitment of EZH2 to alter H3K27me3 levels at the promoter region of PDCD4. In addition, SET-binding factor 2 antisense RNA1 (SBF2-AS1) was demonstrated to bind to SUZ12 and guide PRC2 to the promoter of CDKN1A to decrease CDKN1A expression in ESCC [33].

The acetylation of histone $\mathrm{H} 3$ and $\mathrm{H} 4$ is another core mechanism through which chromatin structure and gene expression are altered [34]. In addition to recruiting EZH2, CASC9 also associates with the transcriptional coactivator CBP in the nucleus to increase the enrichment of CBP and H3K27 acetylation in the promoter region of LAMC2, thereby increasing LAMC2 expression [35].

DNA methylation is one of the most common and stable chromatin modification that is associated with gene inactivation [36, 37]. Lung cancer associated transcript 1 (LUCAT1) was originally identified in smokingrelated lung cancer [38] and is also associated with colorectal cancer [39], clear cell renal cell carcinoma, and osteosarcoma [40]. A recent study demonstrated that LUCAT1 binds to DNMT1, the most abundant DNA methyltransferase in mammalian cells, and regulates its stability by inducing the ubiquitination of DNMT1 in ESCC [41]. The high levels of LUCAT1 in ESCC inhibit the expression of certain tumor suppressors through DNA methylation.

In addition, NMR, a novel lncRNA identified through microarray assays, was found to be upregulated in ESCC tissues and primarily located in the cell nucleus [42]. NMR interacts with the chromatin regulator BPTF [42], which was demonstrated to be involved in ATPdependent chromatin remodeling and transcriptional regulation [43]. Hence, by recruiting BPTF to specific loci of chromatin, NMR upregulates the expression of MMP3 and MMP10 via ERK1/2 activation to promote ESCC tumorigenesis. 


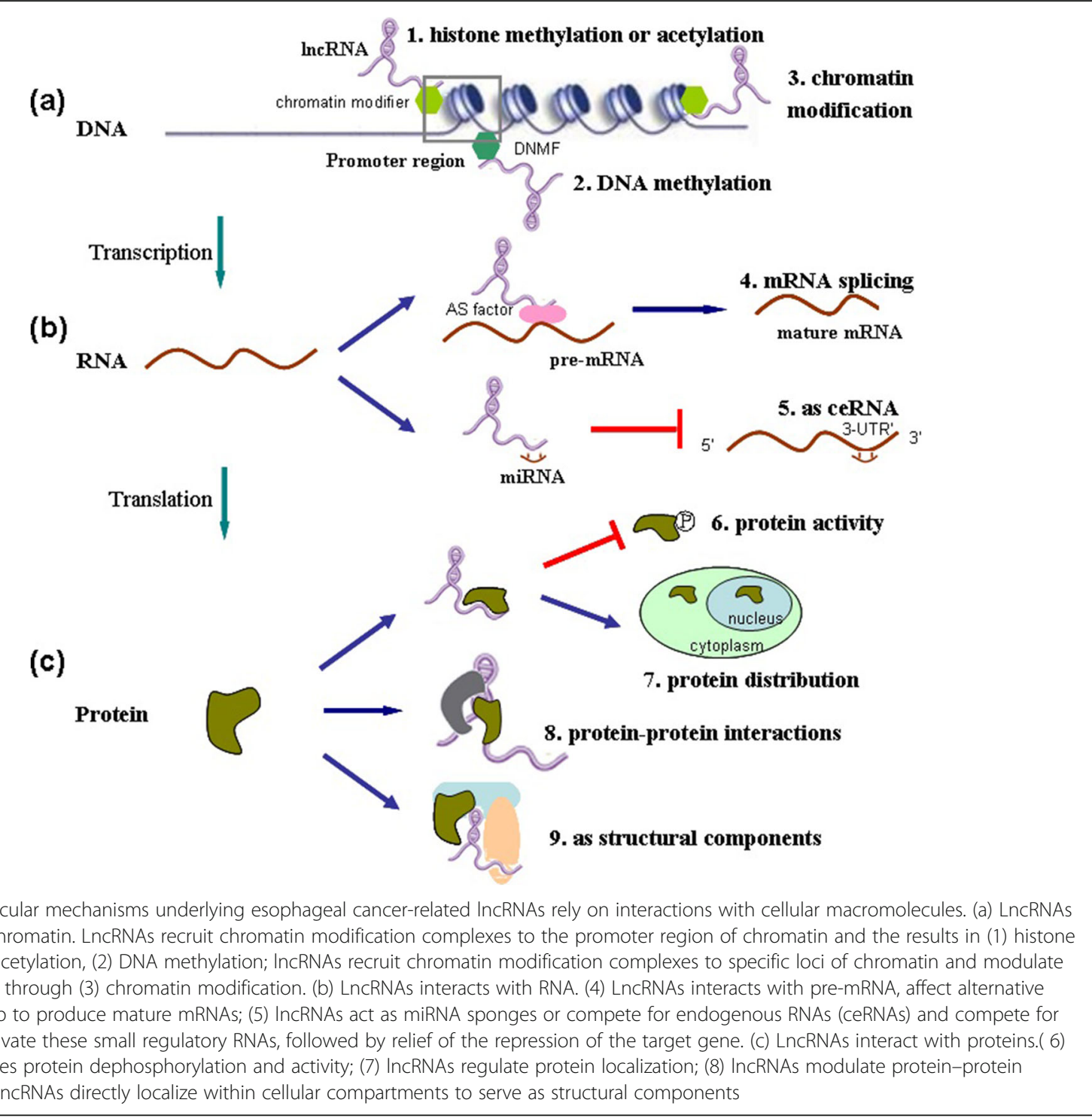

\section{LncRNAs target RNA}

Following the transcription of RNA in the nucleus, a series of conserved processes are essential for the production of mature mRNAs that can be translated into proteins. LncRNAs modulate gene expression at the RNA level through the regulation of alternative splicing and the stability of mRNAs; additionally, lncRNAs act as miRNA sponges or competing endogenous RNAs (ceRNAs) $[17,26]$.

\section{mRNA splicing}

Alternative splicing is a regulated process that produces different mRNA splice isoforms from a single mRNA precursor [44]. Alternative splicing produces different proteins that are translated from alternatively spliced mRNAs. This process results in proteins that have different biological functions and phenotypes [45, 46]. LincRNA-uc002yug.2, a
lncRNA principally localized to the nucleus, is increased significantly in ESCC tissues [47]. LincRNA-uc002yug.2 was shown to promote the recruitment of alternative splicing factors and RUNX1 to the nucleus to produce more RUNX1a (an inhibitor of RUNX1) relative to the other two isoforms (RUNX1b and RUNX1c) [48]. Moreover, decreased RUNX1 expression was shown to reduce the mRNA levels of CEBP $\alpha$, which promotes cell proliferation [49]. Thus, LincRNA-uc002yug.2 may modulate cell proliferation and the tumor growth of ESCC through the alternative splicing of RUNX1.

\section{CeRNA}

The ceRNA hypothesis is a novel theory regarding the regulation of gene expression through post-transcriptional processes [50]. According to this hypothesis, ceRNA acts as a molecular sponge for common miRNAs through the 
Table 1 Molecular mechanisms of deregulated IncRNAs in EC

\begin{tabular}{|c|c|c|c|c|}
\hline Mode of mechanism & LncRNA & Expression & Molecular mechanisms & Ref. \\
\hline \multirow{5}{*}{$\begin{array}{l}\text { Localizes to } \\
\text { chromatin }\end{array}$} & CASC9 & Up & Negatively regulates PDCD4 expression through recruiting EZH2 and altering H3K27me3 level & [32] \\
\hline & SBF2-AS1 & Up & $\begin{array}{l}\text { Binds with PRC2 and guided PRC2 to the promoter of CDKN1A and decreased } \\
\text { CDKN1A expression }\end{array}$ & [33] \\
\hline & CASC9 & Up & $\begin{array}{l}\text { Activates the FAK-PI3K/Akt signaling pathways through upregulating LAMC2 expression } \\
\text { by interacting with the CREB-binding protein }\end{array}$ & [35] \\
\hline & LUCAT1 & & $\begin{array}{l}\text { Binds to DNMT1 and regulates its stability, inhibits the expression of tumor suppressors } \\
\text { through DNA methylation }\end{array}$ & [41] \\
\hline & NMR, & & $\begin{array}{l}\text { Interacts with BPTF and recruits it to chromatin, upregulates expression of MMP3 and } \\
\text { MMP10 via ERK1/2 activation }\end{array}$ & [42] \\
\hline $\begin{array}{l}\text { Interacts with RNA } \\
\text { (mRNA splicing) }\end{array}$ & $\begin{array}{l}\text { LincRNA- } \\
\text { uc002yug.2 }\end{array}$ & Up & Associates with alternative splicing of RUNX1 & [48] \\
\hline \multirow{10}{*}{$\begin{array}{l}\text { Interacts with RNA } \\
\text { (ceRNA) }\end{array}$} & ATB & Up & Regulates miR-200b/Kindlin-2 axis & [51] \\
\hline & SNHG16 & Up & Regulates miR-140-5p/ZEB1 axis & [54] \\
\hline & HOTAIR & Up & Regulates miR-125/HK2 and miR-143/HK2 axis, miR-148a/Snail2 axis, miR-1/CCND1 axis & $\begin{array}{l}{[61][64]} \\
{[65]}\end{array}$ \\
\hline & CCAT1 & Up & Regulates miR-7/HOXB13 axis & [69] \\
\hline & NEAT1 & Up & Regulates miR-129/CTBP2 axis & [70] \\
\hline & PVT1 & Up & Regulates miR-203/LASP1 axis & [71] \\
\hline & SNHG1 & Up & Regulates miR-338/CST3 axis & [72] \\
\hline & UCA1 & Up & Regulates miR-204/ Sox4 axis & [73] \\
\hline & XIST & Up & Regulates miR-101/EZH2 axis & [74] \\
\hline & TUSC7 & Down & Regulates miR-224/DESC1 axis & [75] \\
\hline \multirow[t]{2}{*}{ Interacts with protein } & LINC01503 & Up & Activates ERK signaling via MAPK and increases AKT signaling & [78] \\
\hline & EZR-AS1 & Up & Upregulates EZR expression by causing SMYD3 redistribution & [85] \\
\hline
\end{tabular}

miRNA response elements (MREs) to regulate the expression of the target genes of the miRNAs. Several lncRNAs have recently been found to act as ceRNAs by sponging miRNAs to reduce their inhibitory effect on their target protein-coding mRNAs.

There are numerous examples of lncRNAs functioning as sponges and therefore oncogenes in EC. Transforming growth factor $\beta$ (ATB) may act as a ceRNA of miR-200b and thereby promote the expression of kindlin-2 in ESCC, as miR-200b potentially targets the $3^{\prime}$-untranslated region (3'-UTR) of kindlin-2 [51]. Kindlin-2 was reported to act as an oncogene by participating in cytoskeleton shaping via RhoA/FAK signaling to modulate cell migration [52, 53]. Moreover, ATB is overexpressed in ESCC. The knockdown of ATB resulted in the suppression of activated RhoA and phosphorylated FAK and the inhibition of ESCC cell proliferation, migration, and lung metastasis. Hence, the dysregulation of the lnc-ATB/miR-200b/kindlin-2 axis is involved in the development of ESCC. Small nucleolar RNA host gene 16 (SNHG16) is significantly upregulated in ESCC, and this lncRNA is primarily distributed within the cytoplasm [54]. SNHG16 promotes the progression of ESCC cells by binding with miR-140-5p to positively regulate the miR-140-5p target gene ZEB1. The transcription factor ZEB1 has been reported to promote the epithelial-to-mesenchymal transition (EMT) in multiple tumors, including ESCC $[55,56]$. Thus, SNHG16 functions as an oncogene by promoting tumor progression by competing with miR-140-5p to regulate ZEB1.

HOX transcript antisense RNA (HOTAIR) is a wellstudied lncRNA that was shown to have multiple ceRNA regulatory roles in EC. HOTAIR is transcribed from the antisense strand of the HOXC gene cluster [57] and has been shown to be involved in reprogramming chromatin organization and promoting cancer cell proliferation and metastasis [58-60]. Ma et al. [61] reported that HOTAIR upregulates the expression of $\mathrm{HK} 2$ by functioning as a molecular sponge for miR-125 and miR-143, both of which modulate HK2 expression by targeting the 3'UTR of $\mathrm{HK} 2$. HK2 is overexpressed in a variety of cancers and is well-known to play a key role in tumor growth and metastasis $[62,63]$. Hence, HOTAIR plays an oncogenic role in ESCC. Another study by $\mathrm{Xu}$ et al. [64] showed that HOTAIR promoted EC cell invasion and metastasis by promoting the EMT through the upregulation of Snail2, a transcription factor associated with the EMT. Mechanistically, HOTAIR positively regulates Snail2 by sponging miR-148a. HOTAIR has also been 
reported to bind directly to miR-1 and act as an endogenous sponge to inhibit miR-1 expression [65], thereby positively regulating CCND1 expression. CCND1 functions as an oncogene in various human cancers by promoting G1-S progression to regulate the cell cycle [66-68]. Thus, the HOTAIR/miR-1/CCND1 axis may promote ESCC tumorigenesis.

Several other lncRNAs have also been shown to function as oncogenes through sponging miRNAs and positively regulating their target tumor-promoting genes, including CCAT1 [69], NEAT1 [70], plasmacytoma variant translocation 1 (PVT1) [71], small nucleolar RNA host gene 1 (SNHG1) [72], UCA1 [73], and XIST [74].

In addition to these oncogenic lncRNAs sponges, there are also lncRNA sponges involved in tumor suppression. Tumor suppressor candidate 7 (TUSC7) is downregulated in ESCC tissues and is associated with shorter OS time in ESCC patients [75]. TUSC7 was shown to bind to and negatively regulate the expression of miR-224, which specifically binds to the 3'UTR region of DESC1 to negatively regulate DESC1 expression. DESC1 is an epithelial-specific enzyme and exerts tumor suppressive roles by promoting cell apoptosis via the downregulation of the EGFR/AKT pathway in ESCC [76, 77]. Thus, TUSC7 promotes cell apoptosis and suppresses the proliferation and chemotherapy resistance of ESCC cells by regulating the DESC1/EGFR/AKT pathway through miR-224. These findings indicate that TUSC7 may act as a tumor suppressor in ESCC.

\section{LncRNAs interact with proteins}

Several lncRNAs have been reported to interact with specific proteins to participate in global cellular processes in EC by regulating protein activity and function, modulating protein-protein interactions or directing the localization of proteins within cellular compartments to serve as structural components [26].

Through RNA pull-down assays and chromatin isolation by RNA purification (ChIRP), Xie and colleagues [78] demonstrated that LINC01503 could bind with both EBP1 and ERK2 in the cytoplasm. Further analysis revealed that both basal and EGF- and IGF-induced phosphorylation of ERK1/2, Akt, p70S6K, and mTOR were significantly decreased following the knockdown of LINC01503. In addition, silencing LINC01503 expression increased the binding of EBP-1 to the PI3K subunit p85, suggesting that LINC01503 inhibits PI3K deubiquitination to activate the PI3K/Akt signaling pathway. Taken together, these findings suggest that LINC01503 contributes to ESCC cell proliferation, migration, and invasion through the activation of the ERK/MAPK and PI3K/Akt signaling pathways.

Snail, an important transcription factor influencing the EMT, binds to the E-box site in the promoter region of E-cad to suppress E-cad expression [79, 80].
This suppression triggers the EMT in a variety of cancer types, including ESCC [81, 82]. Thus, the nuclear localization of Snail is crucial for its role in the EMT progression [83]. A study by Zhang et al. [84] showed that Sprouty4-Intron 1 (SPRY4-IT1) directly increased the transcription and expression of Snail, as well as its nuclear localization, by directly binding with Snail in ESCC cells. SPRY4-IT1 is highly expressed in ESCC tissues, and overexpression of SPRY4-IT1 promotes the EMT in ESCC cells. This finding demonstrates that SPRY4-IT1 may act as an oncogene in ESCC progression via the regulation of Snail.

EZR-antisense 1 (EZR-AS1) interacts with and is part of the RNA polymerase II complex [85]. RIP assays have revealed that EZR-AS1 directly binds with SMYD3, a histone H3-lysine 4 (H3K4)-specific methyltransferase, causing SMYD3 redistribution and recruiting SMYD3 to the binding site in $\mathrm{GC}$-rich regions downstream of the EZR promoter in ESCC cells. This recruitment results in the localized enrichment of SMYD3 and H3K4me3 in the EZR promoter. Lastly, EZR-AS1 was shown to promote ESCC cell migration via enhancing EZR transcription and expression.

\section{Functions of IncRNAs in EC}

Increasing evidence in the last decade indicates that lncRNAs function in a plethora of biological processes, including cell survival and apoptosis, cell cycle progression and proliferation, migration and invasion, stemness, and chemoradiotherapy (CRT) resistance (Table 2).

\section{Involvement of IncRNAs in the hallmarks of cancer}

Although cancer is a complex and heterogeneous disease, one of the common features of cancer is that abnormal cells grow beyond control. In 2000, Hanahan and Weinberg proposed six properties that are the hallmarks of cancer [86]. These basic hallmarks include sustaining growth signaling, evading growth inhibitors, uncontrolled replicative immortality, tissue invasion and metastasis, promoting angiogenesis, and resisting cell death.

\section{Sustaining growth signaling}

Tumor cells acquire the capability to sustain growth signaling through autocrine and paracrine growth factor pathways [87]. LncRNAs mediate tumor growth signals primarily by acting on the regulation of growth factors or receptors. Epidermal growth factor receptor (EGFR) is a crucial regulator in tumor growth [67]. LINC00152 has been reported to directly bind to EGFR and activate the downstream PI3K/AKT signaling pathway in gastric cancer [88]. Recently, Yang and colleagues [89] demonstrated that both LINC00152 and EGFR were highly 
Table 2 Functions of deregulated IncRNAs in EC

\begin{tabular}{|c|c|c|c|c|}
\hline Function & LncRNA & Expression & Targets & Ref. \\
\hline Sustaining growth signaling & LINC00152 & Up & EGFR & {$[89]$} \\
\hline \multirow[t]{2}{*}{ Evading growth inhibitors } & AK001796 & Up & MDM2/p53 signaling & {$[93]$} \\
\hline & CASC2 & Down & miR-18a-5p/PTEN axis & [99] \\
\hline \multirow[t]{2}{*}{ Uncontrolled replicative immortality } & CDKN2B-AS1 & Up & hTERT & {$[104]$} \\
\hline & BC032469 & Up & hTERT & {$[105]$} \\
\hline \multirow[t]{9}{*}{ Activating invasion and metastasis } & PVT1 & Up & - & {$[106]$} \\
\hline & SNHG16 & Up & miR-140-5p/ZEB1 axis & {$[54]$} \\
\hline & HOTAIR & Up & miR-148a/Snail2 axis & {$[64]$} \\
\hline & SNHG1 & Up & Notch pathway & [112] \\
\hline & MALAT1 & Up & Ezh2-Notch1 signaling, miR-200a/ZEB1, and miR-200a/ZEB2 axis & [113] [114] \\
\hline & CASC9 & Up & - & {$[115]$} \\
\hline & GHET1 & Up & - & [116] \\
\hline & TTN-AS1 & Up & miR-133b/Snail1 axis, miR-133b/FSCN1 axis HuR & {$[117]$} \\
\hline & HOTTIP & Up & miR-30b/HOXA13 axis & {$[118,119]$} \\
\hline Promoting angiogenesis & HNF1A-AS1 & Up & VEGF & [123] \\
\hline \multirow[t]{4}{*}{ Resisting apoptosis } & TP73-AS1 & Up & $\mathrm{BDH} 2$ & {$[126]$} \\
\hline & POU6F2-AS2 & Up & Ybx1 & {$[127]$} \\
\hline & AFAP1-AS1 & Up & - & [128] \\
\hline & LET & Down & - & [129] \\
\hline \multirow[t]{4}{*}{ Chemoradiotherapy resistance } & AFAP1-AS1 & Up & - & [132] \\
\hline & LOC285194 & Up & - & [136] \\
\hline & BOKAS & Up & WISP1 & {$[47]$} \\
\hline & TUSC7 & down & miR-224/DESC1 & {$[75]$} \\
\hline Regulation of EC stem cells & MALAT1 & Up & OCT4 and Nanog & {$[147]$} \\
\hline
\end{tabular}

expressed in the subtype 1 of ESCC. By performing differential coexpression analysis (DCEA) and traditional differential expression analysis (DEA), the authors detected the "gain" of miRNA-mediated crosstalk between EGFR and LINC00152 in ESCC. However, the exact regulatory relationship between LINC00152 and EGFR needs further clarification.

\section{Evading growth inhibitors}

Several tumor suppressors that regulate the cell cycle and inhibit cellular growth have been discovered, such as p53 and PTEN [87]. Certain lncRNAs regulate EC cell growth through altering the expression of these tumor suppressors. P53 is a master "gatekeeper" of the cell and functions as a tumor suppressor gene [90]. P53 regulates the expression of numerous target genes, which leads to the suppression of tumor growth through the induction of cell cycle arrest and apoptosis. Mouse double minute 2 (MDM2), which acts as a primary regulator of $\mathrm{p} 53$, inhibits the transcription of $\mathrm{p} 53$ via promoting its ubiquitination and degradation [91, 92]. Thus, the MDM2/p53 axis is an important signaling pathway that regulates cell growth and the cell cycle. The expression of lncRNA
AK001796 was shown to be positively associated with MDM2 levels in ESCC tissues [93]. Knockdown of AK001796 downregulated the expression of MDM2 and upregulated the expression of p53 along with its target gene, p21. Taken together, these findings indicate that AK001796 mediates the cell cycle and cell proliferation by activating p53 signaling.

Another important tumor suppressor is PTEN, which is a crucial inhibitor of the PI3K/AKT/Mtor pathway [94, 95]. This signaling pathway is a well-known regulator of the cell cycle, proliferation, migration, and apoptosis [9698]. Zhang et al. [99] reported that miR-18a-5p directly binds to the 3'UTR regions of PTEN, thereby inhibiting the expression of PTEN in EC cells. In addition, lncRNA cancer susceptibility candidate 2 (CASC2) was demonstrated to directly interact with miR-18a-5p and modulate the expression of PTEN by targeting miR-18a-5p. These data revealed that CASC2 may inhibit the proliferation of EC cells.

\section{Uncontrolled replicative immortality}

The telomeres, located at the chromosome ends, are important for limiting cell division cycles and replication. 
Telomerase was shown to regulate the expression of a variety of growth-controlling genes and promote cell proliferation $[100,101]$. As a catalytic subunit of telomerase, human telomerase reverse transcriptase (hTERT) maintains the telomere length and plays crucial roles in cell proliferation [102, 103]. Hu et al. [104] reported that hTERT expression is mediated by lncRNA cyclindependent kinase inhibitor 2B-antisense 1 (CDKN2BAS1). Thus, the knockdown of CDKN2B-AS1 rescued the slow proliferation of EC109 cells induced by $\beta$-elemene, an anticancer drug. BC032469, another IncRNA that is overexpressed in ESCC tissues, was positively associated with a larger tumor size and shorter OS [105]. Silencing BC032469 expression in ESCC cells resulted in the inhibition of cell proliferation. Mechanical assays revealed that BC032469 induced cell cycle arrest in the G0/G1 phase by regulating the expression of hTERT.

\section{Activating invasion and metastasis}

The process of EMT has been confirmed to play a critical role in cell invasion in various types of cancer. This process transforms adherent and polarized epithelial cells into invasive and motile mesenchymal cells, accompanied with the loss of epithelial markers E-cadherin and the acquisition of mesenchymal markers $\mathrm{N}$-cadherin and vimentin. Multiple lncRNAs have been demonstrated to be involved in EC development through the regulation of the EMT and metastasis. PVT1 has been identified as an oncogene, and high PVT1 expression was shown to be associated with the development of EC. Upregulation of PVT1 in EC cells resulted in increased $\mathrm{N}$-cadherin and vimentin expression and decreased E-cadherin expression [106]. Thus, PVT1 induced the EMT and promoted the invasion of EC cells.

The EMT is also induced by several signaling pathways, such as the TGF- $\beta$ and Notch signaling pathways [107-109]. The Notch signaling pathway is important for the development and progression of some tumors $[110,111]$. The lncRNA SNHG1 was shown to be overexpressed in ESCC tissues and correlated with lymph node metastasis, depth of invasion, and shorter OS time in ESCC patients [112]. Silencing the expression of SNHG1 in ESCC cells was demonstrated to inhibit cell proliferation and cell invasion capacity, as well as the EMT phenomenon, through suppressing the Notch signaling pathway.

Additional lncRNAs involved in the EMT and invasion of EC include SNHG16 [54], HOTAIR [64], SNHG1 [112], metastasis associated in lung adenocarcinoma transcript 1 (MALAT1) [113, 114], CASC9 [115], gastric carcinoma highly expressed transcript 1 (GHET1) [116], TTN-antisense 1 (TTN-AS1) [117], and HOXA transcript at the distal tip (HOTTIP) [118, 119].

\section{Promoting angiogenesis}

Angiogenesis is a universal characteristic of EC progression, as it supplies the tumor with nutrients and oxygen and facilitates proliferation and migration [120, 121]. Vascular endothelial growth factor (VEGF) is the most potent activator of angiogenesis [122]. LncRNAs may regulate angiogenesis primarily by regulating VEGF. HNF1A-antisense 1 (HNF1A-AS1) is the sole lncRNA reported to modulate VEGF thus far. Recently, Wang reported that the knockdown of HAS1 suppressed the expression of VEGF in ESCC cells [123]. However, direct supporting evidence that HAS1 inhibits angiogenesis requires further studies.

\section{Resisting cell death}

The following three major pathways lead to cell death: apoptosis, autophagy, and necrosis [124]. Currently, few lncRNAs are known to be associated with the latter two pathways of cell death in EC, but several lncRNAs are involved in apoptosis via regulating the transcription of key apoptotic factors. For instance, BDH2, which functions as an anti-apoptotic factor, is regulated by survivin via the caspase-3-independent pathway [125]. P73 antisense RNA 1T (TP73-AS1), a lncRNA mapped to chromosome $1 \mathrm{p} 36.32$, was shown to mediate apoptosis via $\mathrm{BDH} 2$ [126]. The knockdown of TP73-AS1 suppressed $\mathrm{BDH} 2$ expression and induced the expression of pro-apoptotic proteins, which subsequently induced apoptosis in EC cells. POU6F2-antisense 2 (POU6F2-AS2) is a lncRNA that is especially overexpressed in ESCC tissues and cells other than EAC [127]. POU6F2AS2 knockdown induced prolonged DNA tails in ESCC cells following ionizing radiation (IR) and caused sensitivity to IR, indicating that POU6F2-AS2 is involved in the DNA damage response. Mechanical assays revealed that POU6F2-AS2 interacts with DNA repair-related protein $\mathrm{Ybx} 1$ and mediates the recruitment of $\mathrm{Ybx} 1$ to the promoter region of target genes, such as p53 and CCNB1. Finally, the dysregulation of POU6F2-AS2 expression in ESCC cell lines regulates cell survival after IR. However, the exact underlying mechanism of several other IncRNAs involved in apoptosis of EC cells, such as AFAP1-AS1 [128] and Low Expression in Tumor (LET) [129], warrants further investigation.

\section{LncRNAs related to chemoradiotherapy resistance}

Acquired CRT resistance is one of the major obstacles in the treatment of EC [130]. Studies have shown that less than $50 \%$ of patients benefit from CRT treatment, and the remaining half patients present resistance to CRT [131]. Recently, several lines of evidence have suggested that lncRNAs are likely to play vital roles in CRT resistance in EC. Zhou et al. [132] examined 18 lncRNAs that were previously reported to be dysregulated in EC or 
involved in CRT resistance in cisplatin-resistant ESCC cell lines and samples from patients treated with dCRT. The authors detected that three IncRNAs (AFAP1-AS1, UCA1, and HOTAIR) were dysregulated in cisplatin-resistant cells compared with the parent cell line. Moreover, AFAP1-AS1 was significantly overexpressed in tumor tissues compared to the adjacent paired tissues. Furthermore, the overexpression of AFAP1-AS1 was strongly related to the response to dCRT and to the shorter progression-free survival (PFS) and OS of ESCC patients. High AFAP1-AS1 expression could predict resistance to CRT in patients with ESCC. Another IncRNA, LOC285194, also known as LSAMP antisense RNA 3, has been reported to be downregulated in several cancers, including EC and was found to be closely associated with a poor patient prognosis [133-135]. Additionally, the low expression of LOC285194 could predict resistance to CRT [136]. As mentioned above, TUSC7 promotes cell apoptosis and inhibits chemotherapy resistance through the miR-224-dependent regulation of DESC1 [75].

Tumor radioresistance is very complex and heterogeneous. Although the mechanism underlying radioresistance is not well-understood, several signaling pathways have been demonstrated to be involved in radioresistance. The Wnt/B-catenin pathway is well-known to promote cell growth and survival and has been proven to modulate radioresistance in various cancers [137, 138]. WISP1, a Wnt- and $\beta$-catenin-responsive gene, mediates radioresistance primarily through suppressing irradiation-induced DNA damage and activating PI3K kinase [139]. Zhang and colleagues [47] reported that ESCC patients with high WISP1 expression had a significantly poorer prognosis compared with those with low WISP1 levels after radiotherapy. The authors further assayed the expression of 94 cancer-related lncRNAs in WISP1-overexpressed EC cells that received radiation, and they identified 14 upregulated lncRNAs and 5 downregulated lncRNAs. Among these lncRNAs, BOKAS was strongly associated with the irradiation-induced upregulation of WISP1. BOKAS is a natural antisense transcript of $\mathrm{BOK}$, a member of the pro-apoptotic Bcl-2 family. Moreover, the downregulation of BOKAS decreased WISP1 expression and greatly enhanced irradiation-induced DNA damage in EC cells. Taken together, these findings indicate that BOKAS induces radioresistance via promoting the upregulation of WISP1.

\section{LncRNAs in the regulation of cancer stem cells}

CSCs only represent a small portion of cells within a given cancer, but they are believed to be responsible for self-renewal, metastatic ability, tumorigenicity, and therapeutic resistance [140-143]. Although ECSCs play a critical role in EC, only a few lncRNAs have been discovered to be associated with the functions of these cells. As an example, MALAT1 has been demonstrated to be associated with tumor stem regulation in several cancer types [144-146]. A recent study by Wang et al. [147] reported that the downregulation of MALAT1 repressed the cancer stem cell-like traits of ECSS through decreasing the expression of tumor stem genes OCT4 and Nanog.

\section{Clinical applications of IncRNAs in EC}

It is recognized that the delayed diagnosis of EC results in metastasis and recurrence and is therefore a major obstacle for EC therapy. Recent studies have demonstrated that lncRNAs play a vital role in the pathological progression of EC. More importantly, lncRNAs have tissue and cell-type specificity. These patterns make lncRNAs attractive as potential biomarkers for the diagnosis and prognosis of EC (Table 3).

\section{Tumor diagnosis}

Emerging evidence has demonstrated that early diagnosis and effective intervention improves the survival of EC patients. LncRNAs are involved in EC oncogenesis and progression, and the presence of lncRNAs in the peripheral blood and body fluids of EC patients suggests that lncRNAs could serve as diagnostic biomarkers [89, 90]. Tong et al. [148] analyzed the levels of ten IncRNAs in 48 plasma samples and found that POU class 3 homeobox 3 (POU3F3), HNF1A-AS1, and SPRY4-IT1 were markedly higher in ESCC patients compared to healthy controls. In addition, in a cohort of 147 ESCC patients and 123 healthy volunteers, the receiver operating characteristics (ROC) curves demonstrated a strong separation between ESCC patients and healthy volunteers, with an area under the curve (AUC) of 0.842 (95\% CI $0.794-0.890 ; p<0.001)$ for POU3F3, with a $72.8 \%$ sensitivity and $89.4 \%$ specificity. In another study, $\mathrm{Hu}$ and colleagues [149] found that Linc00152, CASP8- and FADD-like apoptosis regulator-antisense 1 (CFLARAS1), and POU3F3 were significantly upregulated in a large cohort of 205 ESCC patients and 82 esophagus dysplasia patients compared to 210 healthy controls, with an AUC of $0.698,0.651$, and 0.584 , respectively. The merged AUCs of the three lncRNAs were 0.765 , while the AUC increased to 0.955 after merging the three factors with CEA. The circulating levels of the three lncRNAs were associated with poor postsurgery prognoses of ESCC patients in Kaplan-Meier curves. The authors also demonstrated the stability of the lncRNAs that were expressed in the human plasma, which is a crucial prerequisite for a biomarker. HOTAIR was shown to be significantly upregulated in ESCC tissues $[150,151]$. A recent study demonstrated that the 
Table 3 The potential clinical applications of deregulated IncRNAs in EC

\begin{tabular}{|c|c|c|c|c|c|}
\hline $\begin{array}{l}\text { Potential } \\
\text { application }\end{array}$ & LncRNA & Expression & Clinical significance & Sample size & Ref. \\
\hline \multirow[t]{3}{*}{$\begin{array}{l}\text { Diagnostic } \\
\text { biomarker }\end{array}$} & POU3F3 & Up & - & $\begin{array}{l}\text { Plasma of } 147 \text { ESCC patients and } 123 \text { healthy } \\
\text { donors }\end{array}$ & [148] \\
\hline & $\begin{array}{l}\text { Linc00152, CFLAR-AS1, } \\
\text { and POU3F3 }\end{array}$ & Up & Poor post-surgery prognosis & $\begin{array}{l}\text { Plasma of } 205 \text { ESCC patients, } 82 \text { esophagus } \\
\text { dysplasia patients and } 210 \text { healthy donors }\end{array}$ & [149] \\
\hline & MIR31HG & Down & TNM stage, lymphatic metastasis, and poorer OS & $\begin{array}{l}\text { Plasma of } 205 \text { ESCC patients and } 39 \text { healthy } \\
\text { donors }\end{array}$ & [153] \\
\hline \multirow{9}{*}{$\begin{array}{l}\text { Prognostic } \\
\text { biomarker }\end{array}$} & ATB & Up & TNM stage and poor DFS & 150 paired ESCC tissues & [51] \\
\hline & XIST & Up & Shorter DFS and OS & 127 paired ESCC tissues & [74] \\
\hline & AK001796 & Up & $\begin{array}{l}\text { TNM stages, lymph node metastasis, and } \\
\text { shorter OS }\end{array}$ & 50 paired ESCC tissues & [93] \\
\hline & ZEB1-AS1 & Up & $\begin{array}{l}\text { Tumor grade, depth of invasion, lymph node } \\
\text { metastasis, and shorter DFS and OS }\end{array}$ & 87 paired ESCC tissues & [145] \\
\hline & MALAT1 & Up & $\begin{array}{l}\text { Lymphatic invasion, distant metastasis, tumor } \\
\text { differentiation, and shorter OS }\end{array}$ & 106 paired ESCC tissues & [147] \\
\hline & PCAT-1 & Up & $\begin{array}{l}\text { Lymph node metastasis, TNM stage, and } \\
\text { poorer OS }\end{array}$ & 130 paired ESCC tissues & [161] \\
\hline & NKILA & Down & Tumor size, TNM stage, poor DFS, and OS & 137 paired ESCC tissues & [162] \\
\hline & SPRY4-IT1 & Up & Clinical stage and shorter OS & 92 paired ESCC tissues & [163] \\
\hline & ZFAS1 & Up & Poor OS & 50 paired ESCC tissues & [164] \\
\hline
\end{tabular}

expression level of HOTAIR in the serum of ESCC patients $(n=50)$ was significantly higher compared to healthy controls $(n=20)$, with an AUC of $0.793(95 \% \mathrm{CI}$ 0.692 to $0.895, P<0.01)$ and optimal cutoff values of 0.094 (sensitivity $56.0 \%$, specificity 90.0\%) [152]. In addition, the serum level of HOTAIR was positively correlated with the distant metastasis and TNM stage. MicroRNA-31 host gene (MIR31HG) is another EC-related lncRNA that is significantly upregulated in EC tissues compared to the adjacent normal tissues, as well as in ESCC plasma, compared to the healthy individuals [153]. In addition, plasma MIR31HG was found to differentiate between ESCC patients and healthy individuals by AUC analysis (95\% CI 0.656 to $0.841, P<0.01$ ). These findings indicated that POU3F3, HOTAIR, and MIR31HG may be potential biomarkers for EC diagnosis. However, given that these lncRNAs have been shown to be dysregulated in cancers other than EC [154-160], they may best serve as effective diagnostic biomarkers in $\mathrm{EC}$ in combination with other variables.

\section{Tumor prognosis}

In recent years, great advances have been made in research into lncRNA-related prognostic biomarkers. The aberrant expression of several lncRNAs has been significantly associated with EC prognosis and may serve as potential prognostic predictors.

The expression of prostate cancer-associated ncRNA transcript 1 (PCAT-1) was markedly upregulated in 130 cancerous tissues compared to matched noncancerous tissues in ESCC [161]. High expression levels of PCAT-1 have been correlated with the depth of tumor invasion, lymph node metastasis, and TNM stage. Kaplan-Meier analysis has revealed that patients in the high PCAT-1 group $(n=65)$ had shorter survival times compared with those in the low PCAT-1 group $(n=39)$. The expression of IncRNA ZEB1-AS1 (ZEB1 antisense 1) was significantly upregulated in 87 ESCC tissues compared to the adjacent noncancerous tissues and was significantly associated with the depth of invasion and lymph node metastasis [145]. In addition, from the Kaplan-Meier survival curves, it was observed that the 5-year overall survival (OS) and disease-free survival (DFS) of ESCC patients with high levels of ZEB1-AS1 were shorter compared with those with low levels of ZEB1-AS1.

Additionally, the dysregulation of lncRNAs ATB [51], XIST [74], AK001796 [93], MALAT1 [147], nuclear transcription factor NF- $\mathrm{kB}$ interacting lncRNA (NKILA) [162], SPRY4-IT1 [163], and zinc finger antisense 1 (ZFAS1) [164] has also been demonstrated to be markedly associated with advanced lymph node metastasis, aggressive TNM stage, and shorter survival time. These lncRNAs may also serve as potential prognostic biomarkers for EC.

\section{Conclusions}

$\mathrm{EC}$ is the eighth most frequently diagnosed malignancy worldwide. Due to typically late diagnoses at the advanced stage, combined with lymphatic metastasis, the prognosis of EC patients is poor. Despite advancements 
in surgery, chemo- and radiotherapy treatment over the past decades, few encouraging improvements in the 5-year OS rate of EC patients have been achieved. Moreover, the molecular mechanisms underlying EC tumorigenesis and development are still elusive. Hence, a comprehensive understanding of the molecular pathogenesis and identification of potential biomarkers of this disease are urgently needed. It is now recognized that aberrant expression of lncRNAs is a crucial determinant for human cancer. In this review, we have summarized the molecular mechanisms of lncRNAs and how they function in EC by localizing to the chromatin and interacting with proteins and RNAs. Uncovering the underlying mechanisms of lncRNAs may help us to understand the pathogenesis and progress of EC, including cell apoptosis, proliferation, migration, stemness, and therapy resistance. Furthermore, IncRNAs have the potential to serve as promising biomarkers for diagnosing EC and predicting prognosis and relapse, and they may even be novel attractive targets for clinical therapy of EC. However, there remain significant gaps in our understanding of the functions of lncRNAs in EC; these gaps must be bridged before lncRNAs can be used in clinical practice.

\begin{abstract}
Abbreviations
3'-UTR: 3'-Untranslated regions; AFAP1-AS1: AFAP1-antisense 1; AS: Alternative splicing; ATB: Activated by transforming growth factor $\beta$; AUC: Area under the curve; CASC2: Cancer susceptibility candidate 2; CASC9: Cancer susceptibility candidate 9; CBP: CREB-binding protein; CCAT1: Colon cancer-associated transcript-1; CDKN2B-AS1: Cyclin-dependent kinase inhibitor 2B-antisense 1; ceRNAs: Competing endogenous RNAs; CFLAR-AS1: CASP8 and FADD-like apoptosis regulator-antisense 1; ChIRP: Chromatin isolation by RNA purification; DFS: Disease-free survival; EAC: Esophageal adenocarcinoma; EC: Esophageal cancer; EMT: Epithelialmesenchymal transition; ESCC: Esophageal squamous cell carcinoma; EZRAS1: EZR-antisense 1; GHET1: Gastric carcinoma highly expressed transcript 1; HNF1A-AS1: HNF1A-antisense 1; HOTAIR: HOX transcript antisense RNA; HOTTIP: HOXA transcript at the distal tip; LET: Low Expression in Tumor; IncRNAs: Long non-coding RNAs; LUCAT1: Lung cancer-associated transcript 1; MALAT1: Metastasis associated in lung adenocarcinoma transcript 1; MIR31HG: MicroRNA-31 host gene; MREs: miRNA response elements; NEAT1: Nuclear paraspeckle assembly transcript 1; NKILA: Nuclear transcription factor NF-kB interacting IncRNA; OS: Overall survival; PCAT-1: Prostate cancerassociated ncRNA transcript 1; POU3F3: POU class 3 homeobox 3; POU6F2AS2: POU6F2-antisense 2; PVT1: Plasmacytoma variant translocation 1; ROC: Receiver operating characteristics; SBF2-AS1: SET-binding factor 2 antisense RNA 1; SNHG1: Small nucleolar RNA host gene 1; SNHG16: Small nucleolar RNA host gene 16; SPRY4-IT1: Sprouty4-Intron 1; TF: Transcription factor; TP73-AS1: P73 antisense RNA 1T; TTN-AS1: TTN-antisense 1; TUSC7: Tumor suppressor candidate 7; UCA1: Urothelial carcinoma associated 1; XIST: X-inactive specific transcript; ZEB1-AS: ZEB1 antisense 1; ZFAS1: Zinc finger antisense 1
\end{abstract}

\section{Acknowledgements}

We thank Dr. Kunjian Peng and Yuqin Zhang for the helpful discussion.

\section{Funding}

This work is supported by grants from the National Natural Scientific Foundation of China $(81802947,81472595,81772842)$, Health and Family Planning Commission of Hunan Province (B20180545), and the Natural Science Foundation of Hunan Province (2017JJ2173), Changsha Science and Technology Board (kq1706045).

\section{Authors' contributions}

All authors have contributed to the preparation of this manuscript. All authors have read and approved the manuscript.

Ethics approval and consent to participate

Not applicable

\section{Consent for publication}

Not applicable

\section{Competing interests}

The authors declare that they have no competing interests.

\section{Publisher's Note}

Springer Nature remains neutral with regard to jurisdictional claims in published maps and institutional affiliations.

\section{Author details}

'Department of the 2nd Department of Thoracic Surgery, Hunan Cancer Hospital and The Affiliated Cancer Hospital of Xiangya School of Medicine, Central South University, Changsha 410013, Hunan, People's Republic of China. ${ }^{2}$ Department of the Central Laboratory, Hunan Cancer Hospital and The Affiliated Cancer Hospital of Xiangya School of Medicine, Central South University, Changsha 410013, Hunan, People's Republic of China. ${ }^{3}$ Department of Pharmacy, Xiangya Hospital of Xiangya School of Medicine, Central South University, Changsha 410001, Hunan, People's Republic of China. ${ }^{4}$ Department of Thoracic Radiotherapy, Key laboratory of Translational Radiation Oncology, Department of Radiation Oncology, Hunan Cancer Hospital and The Affiliated Cancer Hospital of Xiangya School of Medicine, Central South University, Changsha 410013, Hunan, People's Republic of China.

Received: 21 July 2018 Accepted: 6 September 2018

Published online: 17 September 2018

\section{References}

1. Holmes RS, Vaughan TL. Epidemiology and pathogenesis of esophageal cancer. Semin Radiat Oncol. 2007;17(1):2-9.

2. Pennathur A, Gibson MK, Jobe BA, Luketich JD. Oesophageal carcinoma. Lancet. 2013;381(9864):400-12.

3. Ohashi S, Miyamoto S, Kikuchi O, Goto T, Amanuma Y, Muto M. Recent advances from basic and clinical studies of esophageal squamous cell carcinoma. Gastroenterology. 2015;149(7):1700-15.

4. Pohl H, Welch HG. The role of overdiagnosis and reclassification in the marked increase of esophageal adenocarcinoma incidence. J Natl Cancer Inst. 2005:97(2):142-6.

5. Rustgi AK, El-Serag HB. Esophageal carcinoma. N Engl J Med. 2014;371(26): 2499-509.

6. Reid BJ, Li X, Galipeau PC, Vaughan TL. Barrett's oesophagus and oesophageal adenocarcinoma: time for a new synthesis. Nat Rev Cancer. 2010;10(2):87-101.

7. Mocanu A, Barla R, Hoara P, Constantinoiu S. Current endoscopic methods of radical therapy in early esophageal cancer. J Med Life. 2015;8(2):150-6.

8. Zheng X, Xing S, Liu XM, Liu W, Liu D, Chi PD, Chen H, Dai SQ, Zhong Q, Zeng MS, et al. Establishment of using serum YKL-40 and SCCA in combination for the diagnosis of patients with esophageal squamous cell carcinoma. BMC Cancer. 2014;14:490.

9. Belkhiri A, El-Rifai W. Advances in targeted therapies and new promising targets in esophageal cancer. Oncotarget. 2015;6(3):1348-58.

10. Qian X, Tan C, Wang F, Yang B, Ge Y, Guan Z, Cai J. Esophageal cancer stem cells and implications for future therapeutics. Onco Targets Ther. 2016;9: 2247-54.

11. Iyer MK, Niknafs YS, Malik R, Singhal U, Sahu A, Hosono Y, Barrette TR, Prensner JR, Evans JR, Zhao $S$, et al. The landscape of long noncoding RNAs in the human transcriptome. Nat Genet. 2015;47(3):199-208.

12. Okazaki Y, Furuno M, Kasukawa T, Adachi J, Bono H, Kondo S, Nikaido I, Osato N, Saito R, Suzuki H, et al. Analysis of the mouse transcriptome based on functional annotation of 60,770 full-length cDNAs. Nature. 2002; 420(6915):563-73. 
13. Ponjavic J, Ponting CP, Lunter G. Functionality or transcriptional noise? Evidence for selection within long noncoding RNAs. Genome Res. 2007; 17(5):556-65.

14. Ma L, Bajic VB, Zhang Z. On the classification of long non-coding RNAs. RNA Biol. 2013;10(6):925-33.

15. Devaux $Y$, Zangrando J, Schroen B, Creemers EE, Pedrazzini T, Chang CP Dorn GW 2nd, Thum T, Heymans S. Long noncoding RNAs in cardiac development and ageing. Nat Rev Cardiol. 2015;12(7):415-25.

16. Batista PJ, Chang HY. Long noncoding RNAs: cellular address codes in development and disease. Cell. 2013;152(6):1298-307.

17. Mercer TR, Dinger ME, Mattick JS. Long non-coding RNAs: insights into functions. Nat Rev Genet. 2009;10(3):155-9.

18. Ponting CP, Oliver PL, Reik W. Evolution and functions of long noncoding RNAs. Cell. 2009;136(4):629-41.

19. Geisler S, Coller J. RNA in unexpected places: long non-coding RNA functions in diverse cellular contexts. Nat Rev Mol Cell Biol. 2013;14(11):699-712.

20. Wang KC, Chang HY. Molecular mechanisms of long noncoding RNAs. Mo Cell. 2011;43(6):904-14

21. Hung T, Wang Y, Lin MF, Koegel AK, Kotake Y, Grant GD, Horlings HM, Shah $\mathrm{N}$, Umbricht $C$, Wang $P$, et al. Extensive and coordinated transcription of noncoding RNAs within cell-cycle promoters. Nat Genet. 2011;43(7):621-9.

22. Tripathi V, Ellis JD, Shen Z, Song DY, Pan Q, Watt AT, Freier SM, Bennett CF, Sharma A, Bubulya PA, et al. The nuclear-retained noncoding RNA MALAT1 regulates alternative splicing by modulating SR splicing factor phosphorylation. Mol Cell. 2010;39(6):925-38.

23. Xie C, Yuan J, Li H, Li M, Zhao G, Bu D, Zhu W, Wu W, Chen R, Zhao Y. NONCODEv4: exploring the world of long non-coding RNA genes. Nucleic Acids Res. 2014:42(Database issue):D98-103.

24. Yan B, Yao J, Liu JY, Li XM, Wang XQ, Li YJ, Tao ZF, Song YC, Chen Q, Jiang Q. IncRNA-MIAT regulates microvascular dysfunction by functioning as a competing endogenous RNA. Circ Res. 2015;116(7):1143-56.

25. Qu J, Li M, Zhong W, Hu C. Competing endogenous RNA in cancer: a new pattern of gene expression regulation. Int J Clin Exp Med. 2015;8(10): 17110-6.

26. Schmitt AM, Chang HY. Long noncoding RNAs in cancer pathways. Cancer Cell. 2016;29(4):452-63.

27. Yang L, Lin C, Jin C, Yang JC, Tanasa B, Li W, Merkurjev D, Ohgi KA, Meng D, Zhang J, et al. IncRNA-dependent mechanisms of androgen-receptorregulated gene activation programs. Nature. 2013;500(7464):598-602.

28. Wang KC, Yang YW, Liu B, Sanyal A, Corces-Zimmerman $R$, Chen Y, Lajoie BR, Protacio A, Flynn RA, Gupta RA, et al. A long noncoding RNA maintains active chromatin to coordinate homeotic gene expression. Nature. 2011; 472(7341):120-4

29. Morlando $M$, Fatica A. Alteration of epigenetic regulation by long noncoding RNAs in cancer. Int J Mol Sci. 2018;19(2).

30. Langevin SM, Kratzke RA, Kelsey KT. Epigenetics of lung cancer. Transl Res. 2015;165(1):74-90

31. Davidovich C, Zheng L, Goodrich KJ, Cech TR, Promiscuous RNA. Binding by polycomb repressive complex 2. Nat Struct Mol Biol. 2013;20(11):1250-7.

32. Wu Y, Hu L, Liang Y, Li J, Wang K, Chen X, Meng H, Guan X, Yang K, Bai Y. Up-regulation of IncRNA CASC9 promotes esophageal squamous cell carcinoma growth by negatively regulating PDCD4 expression through EZH2. Mol Cancer. 2017:16(1):150

33. Chen R, Xia W, Wang X, Qiu M, Yin R, Wang S, Xi X, Wang J, Xu Y, Dong G, et al. Upregulated long non-coding RNA SBF2-AS1 promotes proliferation in esophageal squamous cell carcinoma. Oncol Lett. 2018;15(4):5071-80.

34. Penney J, Tsai LH. Histone deacetylases in memory and cognition. Sci Signal. 2014;7(355):re12.

35. Liang Y, Chen X, Wu Y, Li J, Zhang S, Wang K, Guan X, Yang K, Bai Y. LnCRNA CASC9 promotes esophageal squamous cell carcinoma metastasis through upregulating LAMC2 expression by interacting with the CREBbinding protein. Cell Death Differ. 2018.

36. Sayols-Baixeras S, Irvin MR, Arnett DK, Elosua R, Aslibekyan SW. Epigenetics of lipid phenotypes. Curr Cardiovasc Risk Rep. 2016;10(10).

37. Ghaznavi H, Mahmoodi K, Soltanpour MS. A preliminary study of the association between the ABCA1 gene promoter DNA methylation and coronary artery disease risk. Mol Biol Res Commun. 2018;7(2):59-65.

38. Thai $\mathrm{P}$, Statt $\mathrm{S}$, Chen $\mathrm{CH}$, Liang E, Campbell C, Wu R. Characterization of a novel long noncoding RNA, SCAL1, induced by cigarette smoke and elevated in lung cancer cell lines. Am J Respir Cell Mol Biol. 2013; 49(2):204-11.
39. Chen $Y, Y u X, X u Y$, Shen $H$. Identification of dysregulated IncRNAs profiling and metastasis-associated IncRNAs in colorectal cancer by genome-wide analysis. Cancer Med. 2017;6(10):2321-30.

40. Han Z, Shi L. Long non-coding RNA LUCAT1 modulates methotrexate resistance in osteosarcoma via miR-200c/ABCB1 axis. Biochem Biophys Res Commun. 2018:495(1):947-53.

41. Yoon JH, You BH, Park CH, Kim YJ, Nam JW, Lee SK. The long noncoding RNA LUCAT1 promotes tumorigenesis by controlling ubiquitination and stability of DNA methyltransferase 1 in esophageal squamous cell carcinoma. Cancer Lett. 2018;417:47-57.

42. Li Y, Li J, Luo M, Zhou C, Shi X, Yang W, Lu Z, Chen Z, Sun N, He J. Novel long noncoding RNA NMR promotes tumor progression via NSUN2 and BPTF in esophageal squamous cell carcinoma. Cancer Lett. 2018:430:57-66.

43. Dar AA, Nosrati M, Bezrookove V, de Semir D, Majid S, Thummala S, Sun V, Tong S, Leong SP, Minor D, et al. The role of BPTF in melanoma progression and in response to BRAF-targeted therapy. J Natl Cancer Inst. 2015;107(5).

44. Modrek B, Lee C. A genomic view of alternative splicing. Nat Genet. 2002; 30(1):13-9.

45. Gaur S, Shively JE, Yen Y, Gaur RK. Altered splicing of CEACAM1 in breast cancer: identification of regulatory sequences that control splicing of CEACAM1 into long or short cytoplasmic domain isoforms. Mol Cancer. 2008;7:46.

46. Gu Z, Xia J, Xu H, Frech I, Tricot G, Zhan F. NEK2 promotes aerobic glycolysis in multiple myeloma through regulating splicing of pyruvate kinase. J Hematol Oncol. 2017;10(1):17.

47. Zhang H, Luo H, Hu Z, Peng J, Jiang Z, Song T, Wu B, Yue J, Zhou R, Xie R, et al. Targeting WISP1 to sensitize esophageal squamous cell carcinoma to irradiation. Oncotarget. 2015;6(8):6218-34.

48. Wu H, Zheng J, Deng J, Zhang L, Li N, Li W, Li F, Lu J, Zhou Y. LincRNAuc002yug.2 involves in alternative splicing of RUNX1 and serves as a predictor for esophageal cancer and prognosis. Oncogene. 2015;34(36): 4723-34.

49. Wang H, lakova P, Wilde M, Welm A, Goode T, Roesler WJ, Timchenko NA C/EBPalpha arrests cell proliferation through direct inhibition of Cdk2 and Cdk4. Mol Cell. 2001;8(4):817-28.

50. Salmena L, Poliseno L, Tay Y, Kats L, Pandolfi PP. A ceRNA hypothesis: the Rosetta stone of a hidden RNA language? Cell. 2011;146(3):353-8.

51. Li Z, Wu X, Gu L, Shen Q, Luo W, Deng C, Zhou Q, Chen X, Li Y, Lim Z, et al. Long non-coding RNA ATB promotes malignancy of esophageal squamous cell carcinoma by regulating miR-200b/Kindlin-2 axis. Cell Death Dis. 2017; 8(6):e2888.

52. Ren $Y$, Jin H, Xue Z, Xu Q, Wang S, Zhao G, Huang J, Huang H. Kindlin-2 inhibited the growth and migration of colorectal cancer cells. Tumour Biol. 2015;36(6):4107-14.

53. Guo B, Gao J, Zhan J, Zhang H. Kindlin-2 interacts with and stabilizes EGFR and is required for EGF-induced breast cancer cell migration. Cancer Lett. 2015:361(2):271-81.

54. Zhang K, Chen J, Song H, Chen LB. SNHG16/miR-140-5p axis promotes esophagus cancer cell proliferation, migration and EMT formation through regulating ZEB1. Oncotarget. 2018;9(1):1028-40.

55. Ma J, Zhan Y, Xu Z, Li Y, Luo A, Ding F, Cao X, Chen H, Liu Z. ZEB1 induced miR-99b/let-7e/miR-125a cluster promotes invasion and metastasis in esophageal squamous cell carcinoma. Cancer Lett. 2017:398:37-45.

56. Yokobori T, Suzuki S, Tanaka N, Inose T, Sohda M, Sano A, Sakai M, Nakajima

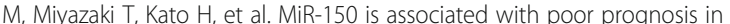
esophageal squamous cell carcinoma via targeting the EMT inducer ZEB1. Cancer Sci. 2013;104(1):48-54.

57. Woo CJ, Kingston RE. HOTAIR lifts noncoding RNAs to new levels. Cell. 2007; 129(7):1257-9.

58. Spizzo R, Almeida Ml, Colombatti A, Calin GA. Long non-coding RNAs and cancer: a new frontier of translational research? Oncogene. 2012;31(43): 4577-87.

59. Wu Y, Zhang L, Wang Y, Li H, Ren X, Wei F, Yu W, Wang X, Yu J, Hao X. Long noncoding RNA HOTAIR involvement in cancer. Tumour Biol. 2014; 35(10):9531-8

60. Loewen G, Jayawickramarajah J, Zhuo Y, Shan B. Functions of IncRNA HOTAIR in lung cancer. J Hematol Oncol. 2014;7:90.

61. Ma J, Fan Y, Feng T, Chen F, Xu Z, Li S, Lin Q, He X, Shi W, Liu Y, et al. HOTAIR regulates HK2 expression by binding endogenous miR-125 and miR-143 in oesophageal squamous cell carcinoma progression. Oncotarget. 2017:8(49):86410-22 
62. Pedersen PL. Warburg, me and hexokinase 2: multiple discoveries of key molecular events underlying one of cancers' most common phenotypes, the "Warburg effect", i.e., elevated glycolysis in the presence of oxygen. J Bioenerg Biomembr. 2007;39(3):211-22.

63. Wolf A, Agnihotri S, Micallef J, Mukherjee J, Sabha N, Cairns R, Hawkins C, Guha A. Hexokinase 2 is a key mediator of aerobic glycolysis and promotes tumor growth in human glioblastoma multiforme. J Exp Med. 2011;208(2):313-26.

64. Xu F, Zhang J. Long non-coding RNA HOTAIR functions as miRNA sponge to promote the epithelial to mesenchymal transition in esophageal cancer. Biomed Pharmacother. 2017:90:888-96.

65. Ren K, Li Y, Lu H, Li Z, Wu K, Han X. Long noncoding RNA HOTAIR controls cell cycle by functioning as a competing endogenous RNA in esophageal squamous cell carcinoma. Transl Oncol. 2016;9(6):489-97.

66. Buschges R, Weber RG, Actor B, Lichter $P$, Collins VP, Reifenberger $G$. Amplification and expression of cyclin D genes (CCND1, CCND2 and CCND3) in human malignant gliomas. Brain Pathol. 1999;9(3):435-42 discussion 432-3.

67. Sunpaweravong $P$, Sunpaweravong S, Puttawibul P, Mitarnun W, Zeng C, Baron AE, Franklin W, Said S, Varella-Garcia M. Epidermal growth factor receptor and cyclin D1 are independently amplified and overexpressed in esophageal squamous cell carcinoma. J Cancer Res Clin Oncol. 2005; 131(2):111-9.

68. Tashiro E, Tsuchiya A, Imoto M. Functions of cyclin D1 as an oncogene and regulation of cyclin D1 expression. Cancer Sci. 2007;98(5):629-35.

69. Zhang E, Han L, Yin D, He X, Hong L, Si X, Qiu M, Xu T, De W, Xu L, et al H3K27 acetylation activated-long non-coding RNA CCAT1 affects cell proliferation and migration by regulating SPRY4 and HOXB13 expression in esophageal squamous cell carcinoma. Nucleic Acids Res. 2017;45(6): 3086-101.

70. Li Y, Chen D, Gao X, Li X, Shi G. LncRNA NEAT1 regulates cell viability and invasion in esophageal squamous cell carcinoma through the miR-129/ CTBP2 Axis. Dis Markers. 2017;2017:5314649.

71. Li PD, Hu JL, Ma C, Ma H, Yao J, Chen LL, Chen J, Cheng TT, Yang KY, Wu G, et al. Upregulation of the long non-coding RNA PVT1 promotes esophageal squamous cell carcinoma progression by acting as a molecular sponge of miR-203 and LASP1. Oncotarget. 2017;8(21):34164-76.

72. Yan Y, Fan Q, Wang L, Zhou Y, Li J, Zhou K. LncRNA Snhg1, a nondegradable sponge for miR-338, promotes expression of proto-oncogene CST3 in primary esophageal cancer cells. Oncotarget. 2017;8(22):35750-60.

73. Jiao C, Song Z, Chen J, Zhong J, Cai W, Tian S, Chen S, Yi Y, Xiao Y. IncRNAUCA1 enhances cell proliferation through functioning as a ceRNA of Sox4 in esophageal cancer. Oncol Rep. 2016;36(5):2960-6.

74. Wu X, Dinglin X, Wang X, Luo W, Shen Q, Li Y, Gu L, Zhou Q, Zhu H, Tan C, et al. Long noncoding RNA XIST promotes malignancies of esophageal squamous cell carcinoma via regulation of miR-101/EZH2. Oncotarget. 2017; 8(44):76015-28

75. Chang ZW, Jia YX, Zhang WJ, Song L, Gao M, Li MJ, Zhao RH, Li J, Zhong YL, Sun QZ, et al. LncRNA-TUSC7/miR-224 affected chemotherapy resistance of esophageal squamous cell carcinoma by competitively regulating DESC1. J Exp Clin Cancer Res. 2018;37(1):56.

76. Kyrieleis OJ, Huber R, Ong E, Oehler R, Hunter M, Madison EL, Jacob U. Crystal structure of the catalytic domain of DESC1, a new member of the type II transmembrane serine proteinase family. FEBS J. 2007; 274(8):2148-60.

77. Ng HY, Ko JM, Yu VZ, Ip JC, Dai W, Cal S, Lung ML. DESC1, a novel tumor suppressor, sensitizes cells to apoptosis by downregulating the EGFR/ AKT pathway in esophageal squamous cell carcinoma. Int J Cancer. 2016;138(12):2940-51.

78. Xie JJ, Jiang YY, Jiang Y, Li CQ, Lim MC, An O, Mayakonda A, Ding LW, Long L, Sun C, et al. Super-enhancer-driven long non-coding RNA LINC01503, regulated by TP63, is over-expressed and oncogenic in squamous cell carcinoma. Gastroenterology. 2018;154(8):2137-2151 e1.

79. Thiery JP, Acloque H, Huang RY, Nieto MA. Epithelial-mesenchymal transitions in development and disease. Cell. 2009;139(5):871-90.

80. Kudo-Saito C, Shirako H, Takeuchi T, Kawakami Y. Cancer metastasis is accelerated through immunosuppression during Snail-induced EMT of cancer cells. Cancer Cell. 2009;15(3):195-206.

81. Kuo KT, Chou TY, Hsu HS, Chen WL, Wang LS. Prognostic significance of NBS1 and Snail expression in esophageal squamous cell carcinoma. Ann Surg Oncol. 2012;19(Suppl 3):S549-57.
82. Natsugoe S, Uchikado Y, Okumura H, Matsumoto M, Setoyama T, Tamotsu K, Kita Y, Sakamoto A, Owaki T, Ishigami S, et al. Snail plays a key role in Ecadherin-preserved esophageal squamous cell carcinoma. Oncol Rep. 2007; 17(3):517-23.

83. Papiewska-Pajak I, Kowalska MA, Boncela J. Expression and activity of SNAIL transcription factor during epithelial to mesenchymal transition (EMT) in cancer progression. Postepy Hig Med Dosw (Online). 2016;70(0):968-80.

84. Zhang CY, Li RK, Qi Y, Li XN, Yang Y, Liu DL, Zhao J, Zhu DY, Wu K, Zhou $X D$, et al. Upregulation of long noncoding RNA SPRY4-IT1 promotes metastasis of esophageal squamous cell carcinoma via induction of epithelial-mesenchymal transition. Cell Biol Toxicol. 2016;32(5):391-401.

85. Zhang XD, Huang GW, Xie YH, He JZ, Guo JC, Xu XE, Liao LD, Xie YM, Song YM, Li EM, et al. The interaction of IncRNA EZR-AS1 with SMYD3 maintains overexpression of EZR in ESCC cells. Nucleic Acids Res. 2018;46(4):1793-809.

86. Hanahan D, Weinberg RA. The hallmarks of cancer. Cell. 2000;100(1):57-70.

87. Gutschner T, Diederichs S. The hallmarks of cancer: a long non-coding RNA point of view. RNA Biol. 2012;9(6):703-19.

88. Zhou J, Zhi X, Wang L, Wang W, Li Z, Tang J, Wang J, Zhang Q, Xu Z. Linc00152 promotes proliferation in gastric cancer through the EGFRdependent pathway. J Exp Clin Cancer Res. 2015;34:135.

89. Yang S, Ning Q, Zhang G, Sun H, Wang Z, Li Y. Construction of differential mRNA-IncRNA crosstalk networks based on ceRNA hypothesis uncover key roles of IncRNAs implicated in esophageal squamous cell carcinoma. Oncotarget. 2016;7(52):85728-40.

90. Levine AJ, Oren M. The first 30 years of p53: growing ever more complex. Nat Rev Cancer. 2009;9(10):749-58.

91. Xie N, Ma L, Zhu F, Zhao W, Tian F, Yuan F, Fu J, Huang D, Lv C, Tong T. Regulation of the MDM2-p53 pathway by the nucleolar protein CSIG in response to nucleolar stress. Sci Rep. 2016;6:36171.

92. Brooks CL, Gu W. p53 ubiquitination: Mdm2 and beyond. Mol Cell. 2006; 21(3):307-15.

93. Liu B, Pan CF, Yao GL, Wei K, Xia Y, Chen YJ. The long non-coding RNA AK001796 contributes to tumor growth via regulating expression of p53 in esophageal squamous cell carcinoma. Cancer Cell Int. 2018;18:38.

94. Yin Y, Shen WH. PTEN: a new guardian of the genome. Oncogene. 2008; 27(41):5443-53.

95. Khalid A, Hussain T, Manzoor S, Saalim M, Khaliq S. PTEN: a potential prognostic marker in virus-induced hepatocellular carcinoma. Tumour Biol. 2017;39(6):1010428317705754.

96. Chalhoub N, Baker SJ. PTEN and the PI3-kinase pathway in cancer. Annu Rev Pathol. 2009:4:127-50

97. Tamura M, Gu J, Matsumoto K, Aota S, Parsons R, Yamada KM. Inhibition of cell migration, spreading, and focal adhesions by tumor suppressor PTEN. Science. 1998;280(5369):1614-7.

98. Choi BH, Xie S, Dai W. PTEN is a negative regulator of mitotic checkpoint complex during the cell cycle. Exp Hematol Oncol. 2017;6:19.

99. Wang D, Gao ZM, Han LG, Xu F, Liu K, Shen Y. Long noncoding RNA CASC2 inhibits metastasis and epithelial to mesenchymal transition of lung adenocarcinoma via suppressing SOX4. Eur Rev Med Pharmacol Sci. 2017; 21(20):4584-90.

100. Smith LL, Coller HA, Roberts JM. Telomerase modulates expression of growth-controlling genes and enhances cell proliferation. Nat Cell Biol. 2003:5(5):474-9.

101. Masutomi K, Yu EY, Khurts S, Ben-Porath I, Currier JL, Metz GB, Brooks MW Kaneko S, Murakami S, DeCaprio JA, et al. Telomerase maintains telomere structure in normal human cells. Cell. 2003;114(2):241-53.

102. Horikawa I, Barrett JC. Transcriptional regulation of the telomerase hTERT gene as a target for cellular and viral oncogenic mechanisms. Carcinogenesis. 2003:24(7):1167-76.

103. Cao Y, Li H, Deb S, Liu JP. TERT regulates cell survival independent of telomerase enzymatic activity. Oncogene. 2002;21(20):3130-8.

104. Hu Z, Wu H, Li Y, Hou Q, Wang Y, Li S, Xia B, Wu S. Beta-Elemene inhibits the proliferation of esophageal squamous cell carcinoma by regulating long noncoding RNA-mediated inhibition of hTERT expression. Anti-Cancer Drugs. 2015;26(5):531-9.

105. Lu C, Yang L, Chen H, Shan Z. Upregulated long non-coding RNA BC032469 enhances carcinogenesis and metastasis of esophageal squamous cell carcinoma through regulating hTERT expression. Tumour Biol. 2016.

106. Zheng X, Hu H, Li S. High expression of IncRNA PVT1 promotes invasion by inducing epithelial-to-mesenchymal transition in esophageal cancer. Oncol Lett. 2016;12(4):2357-62. 
107. Ungefroren $H$, Witte $D$, Lehnert $H$. The role of small GTPases of the rho/Rac family in TGF-beta-induced EMT and cell motility in cancer. Dev Dyn. 2018; 247(3):451-61.

108. Li Y, Ma J, Qian X, Wu Q, Xia J, Miele L, Sarkar FH, Wang Z. Regulation of EMT by notch signaling pathway in tumor progression. Curr Cancer Drug Targets. 2013;13(9):957-62.

109. Wang Z, Li Y, Kong D, Sarkar FH. The role of Notch signaling pathway in epithelial-mesenchymal transition (EMT) during development and tumor aggressiveness. Curr Drug Targets. 2010;11(6):745-51.

110. Venkatesh V, Nataraj R, Thangaraj GS, Karthikeyan M, Gnanasekaran A, Kaginelli SB, Kuppanna G, Kallappa CG, Basalingappa KM. Targeting Notch signalling pathway of cancer stem cells. Stem Cell Investig. 2018;5:5.

111. Tamagnone L, Zacchigna S, Rehman M. Taming the Notch transcriptional regulator for cancer therapy. Molecules. 2018;23(2).

112. Zhang Y, Jin X, Wang Z, Zhang X, Liu S, Liu G. Downregulation of SNHG1 suppresses cell proliferation and invasion by regulating Notch signaling pathway in esophageal squamous cell cancer. Cancer Biomark. 2017; 21(1):89-96

113. Chen M, Xia Z, Chen C, Hu W, Yuan Y. LncRNA MALAT1 promotes epithelialto-mesenchymal transition of esophageal cancer through Ezh2-Notch1 signaling pathway. Anti-Cancer Drugs. 2018;29(8):767-73.

114. Zhang QQ, Cui YH, Wang Y, Kou WZ, Cao F, Cao XJ, Miao ZH, Kang XH. Mechanism of long non-coding RNA-metastasis associated lung adenocarcinoma transcript 1 induced invasion and metastasis of esophageal cancer cell EC-109. Zhonghua Zhong Liu Za Zhi. 2017; 39(6):405-11.

115. Gao GD, Liu XY, Lin Y, Liu HF, Zhang GJ. LncRNA CASC9 promotes tumorigenesis by affecting EMT and predicts poor prognosis in esophageal squamous cell cancer. Eur Rev Med Pharmacol Sci. 2018;22(2):422-9.

116. Xia Y, Yan Z, Wan Y, Wei S, Bi Y, Zhao J, Liu J, Liao DJ, Huang H. Knockdown of long noncoding RNA GHET1 inhibits cell-cycle progression and invasion of gastric cancer cells. Mol Med Rep. 2018;18(3):3375-81.

117. Lin C, Zhang S, Wang Y, Nice E, Guo C, Zhang E, Yu L, Li M, Liu C, Hu $L$, et al. Functional role of a novel long noncoding RNA TTN-AS1 in esophageal squamous cell carcinoma progression and metastasis. Clin Cancer Res. 2018;24(2):486-98

118. Chen X, Han H, Li Y, Zhang Q, Mo K, Chen S. Upregulation of long noncoding RNA HOTTIP promotes metastasis of esophageal squamous cell carcinoma via induction of EMT. Oncotarget. 2016;7(51):84480-5.

119. Lin C, Wang Y, Zhang S, Yu L, Guo C, Xu H. Transcriptional and posttranscriptional regulation of HOXA13 by IncRNA HOTTIP facilitates tumorigenesis and metastasis in esophageal squamous carcinoma cells. Oncogene. 2017;36(38):5392-406

120. Barzi A, Lenz HJ. Angiogenesis-related agents in esophageal cancer. Expert Opin Biol Ther. 2012;12(10):1335-45.

121. Barzi A, Thara E. Angiogenesis in esophageal and gastric cancer: a paradigm shift in treatment. Expert Opin Biol Ther. 2014;14(9):1319-32.

122. Fantozzi A, Gruber DC, Pisarsky L, Heck C, Kunita A, Yilmaz M, Meyer-Schaller N, Cornille K, Hopfer U, Bentires-Alj M, et al. VEGF-mediated angiogenesis links EMT-induced cancer stemness to tumor initiation. Cancer Res. 2014; 74(5):1566-75.

123. Wang G, Zhao W, Gao X, Zhang D, Li Y, Zhang Y, Li W. HNF1AAS1 promotes growth and metastasis of esophageal squamous cell carcinoma by sponging miR214 to upregulate the expression of SOX-4. Int J Oncol. 2017; 51(2):657-67.

124. Chen Q, Kang J, Fu C. The independence of and associations among apoptosis, autophagy, and necrosis. Signal Transduct Target Ther. 2018;3:18.

125. Yang WC, Tsai WC, Lin PM, Yang MY, Liu YC, Chang CS, Yu WH, Lin SF. Human $\mathrm{BDH} 2$, an anti-apoptosis factor, is a novel poor prognostic factor for de novo cytogenetically normal acute myeloid leukemia. J Biomed Sci. 2013;20:58.

126. Zang W, Wang T, Wang Y, Chen X, Du Y, Sun Q, Li M, Dong Z, Zhao G Knockdown of long non-coding RNA TP73-AS1 inhibits cell proliferation and induces apoptosis in esophageal squamous cell carcinoma. Oncotarget. 2016;7(15):19960-74.

127. Liu J, Sun X, Zhu H, Qin Q, Yang X. Long noncoding RNA POU6F2-AS2 is associated with oesophageal squamous cell carcinoma. J Biochem. 2016 160(4):195-204

128. Luo HL, Huang MD, Guo JN, Fan RH, Xia XT, He JD, Chen XF. AFAP1-AS1 is upregulated and promotes esophageal squamous cell carcinoma cell proliferation and inhibits cell apoptosis. Cancer Med. 2016;5(10):2879-85.
129. Wang PL, Liu B, Xia Y, Pan CF, Ma T, Chen YJ. Long non-coding RNA-low expression in tumor inhibits the invasion and metastasis of esophageal squamous cell carcinoma by regulating p53 expression. Mol Med Rep. 2016; 13(4):3074-82.

130. Akutsu Y, Hanari N, Yusup G, Komatsu-Akimoto A, Ikeda N, Mori M, Yoneyama $\mathrm{Y}$, Endo S, Miyazawa Y, Matsubara H. COX2 expression predicts resistance to chemoradiotherapy in esophageal squamous cell carcinoma. Ann Surg Oncol. 2011;18(10):2946-51.

131. Courrech Staal EF, Aleman BM, Boot $H$, van Velthuysen ML, van Tinteren $H$, van Sandick JW. Systematic review of the benefits and risks of neoadjuvant chemoradiation for oesophageal cancer. Br J Surg. 2010;97(10):1482-96.

132. Zhou XL, Wang WW, Zhu WG, Yu CH, Tao GZ, Wu QQ, Song YQ, Pan $P$, Tong YS. High expression of long non-coding RNA AFAP1-AS1 predicts chemoradioresistance and poor prognosis in patients with esophageal squamous cell carcinoma treated with definitive chemoradiotherapy. Mol Carcinog. 2016;55(12):2095-105.

133. Pasic I, Shlien A, Durbin AD, Stavropoulos DJ, Baskin B, Ray PN, Novokmet A Malkin D. Recurrent focal copy-number changes and loss of heterozygosity implicate two noncoding RNAs and one tumor suppressor gene at chromosome 3q13.31 in osteosarcoma. Cancer Res. 2010;70(1):160-71.

134. Liu Q, Huang J, Zhou N, Zhang Z, Zhang A, Lu Z, Wu F, Mo YY. LncRNA loc285194 is a p53-regulated tumor suppressor. Nucleic Acids Res. 2013, 41(9):4976-87.

135. Qi P, Xu MD, Ni SJ, Huang D, Wei P, Tan C, Zhou XY, Du X. Low expression of LOC285194 is associated with poor prognosis in colorectal cancer. J Transl Med. 2013;11:122

136. Tong YS, Zhou XL, Wang XW, Wu QQ, Yang TX, Lv J, Yang JS, Zhu B, Cao XF. Association of decreased expression of long non-coding RNA LOC285194 with chemoradiotherapy resistance and poor prognosis in esophageal squamous cell carcinoma. J Transl Med. 2014;12:233.

137. Chen MS, Woodward WA, Behbod F, Peddibhotla S, Alfaro MP, Buchholz TA Rosen JM. Wnt/beta-catenin mediates radiation resistance of Sca1+ progenitors in an immortalized mammary gland cell line. J Cell Sci. 2007; 120(Pt 3):468-77.

138. Chang HW, Roh JL, Jeong EJ, Lee SW, Kim SW, Choi SH, Park SK, Kim SY. Wnt signaling controls radiosensitivity via cyclooxygenase-2-mediated Ku expression in head and neck cancer. Int J Cancer. 2008;122(1):100-7.

139. Clevers H. Wnt/beta-catenin signaling in development and disease. Cell. 2006;127(3):469-80.

140. Dalerba P, Clarke MF. Cancer stem cells and tumor metastasis: first steps into uncharted territory. Cell Stem Cell. 2007;1(3):241-2.

141. Dean M, Fojo T, Bates S. Tumour stem cells and drug resistance. Nat Rev Cancer. 2005:5(4):275-84

142. Islam F, Gopalan V, Lam AK. Identification of cancer stem cells in esophageal adenocarcinoma. Methods Mol Biol. 2018;1756:165-76.

143. Huang X, Xiao R, Pan S, Yang X, Yuan W, Tu Z, Xu M, Zhu Y, Yin Q, Wu Y, et al. Uncovering the roles of long non-coding RNAs in cancer stem cells. J Hematol Oncol. 2017;10(1):62.

144. Yang MH, Hu ZY, Xu C, Xie LY, Wang XY, Chen SY, Li ZG. MALAT1 promotes colorectal cancer cell proliferation/migration/invasion via PRKA kinase anchor protein 9. Biochim Biophys Acta. 2015;1852(1):166-74.

145. Zhang J, Zhang B, Wang T, Wang H. LncRNA MALAT1 overexpression is an unfavorable prognostic factor in human cancer: evidence from a metaanalysis. Int J Clin Exp Med. 2015;8(4):5499-505.

146. Michalik KM, You X, Manavski Y, Doddaballapur A, Zornig M, Braun T, John D, Ponomareva $Y$, Chen W, Uchida S, et al. Long noncoding RNA MALAT1 regulates endothelial cell function and vessel growth. Circ Res. 2014;114(9):1389-97.

147. Wang W, Zhu Y, Li S, Chen X, Jiang G, Shen Z, Qiao Y, Wang L, Zheng P, Zhang Y. Long noncoding RNA MALAT1 promotes malignant development of esophageal squamous cell carcinoma by targeting beta-catenin via Ezh2. Oncotarget. 2016;7(18):25668-82

148. Tong YS, Wang XW, Zhou XL, Liu ZH, Yang TX, Shi WH, Xie HW, Lv J, Wu QQ, Cao XF. Identification of the long non-coding RNA POU3F3 in plasma as a novel biomarker for diagnosis of esophageal squamous cell carcinoma. Mol Cancer. 2015;14:3

149. Hu HB, Jie HY, Zheng XX. Three circulating LncRNA predict early progress of esophageal squamous cell carcinoma. Cell Physiol Biochem. 2016:40(12):117-25

150. Ge XS, Ma HJ, Zheng $X H$, Ruan HL, Liao XY, Xue WQ, Chen YB, Zhang $Y$, Jia WH. HOTAIR, a prognostic factor in esophageal squamous cell carcinoma, 
inhibits WIF-1 expression and activates Wnt pathway. Cancer Sci. 2013; 104(12):1675-82

151. Da C, Zhan Y, Li Y, Tan Y, Li R, Wang R. The expression and significance of HOX transcript antisense RNA and epithelial-mesenchymal transitionrelated factors in esophageal squamous cell carcinoma. Mol Med Rep. 2017;15(4):1853-62.

152. Wang W, He X, Zheng Z, Ma X, Hu X, Wu D, Wang M, Serum HOTAIR. As a novel diagnostic biomarker for esophageal squamous cell carcinoma. Mol Cancer. 2017;16(1):75.

153. Sun K, Zhao X, Wan J, Yang L, Chu J, Dong S, Yin H, Ming L, He F. The diagnostic value of long non-coding RNA MIR31HG and its role in esophageal squamous cell carcinoma. Life Sci. 2018;202:124-30.

154. Li Y, Wang D, Meng Q. Linc-POU3F3 is overexpressed in hepatocellular carcinoma and regulates cell proliferation, migration and invasion. Biomed Pharmacother. 2018:105:683-9.

155. Xiong G, Yang L, Chen Y, Fan Z. Linc-POU3F3 promotes cell proliferation in gastric cancer via increasing T-reg distribution. Am J Transl Res. 2015; 7(11):2262-9.

156. Shan TD, Xu JH, Yu T, Li JY, Zhao LN, Ouyang H, Luo S, Lu XJ, Huang CZ, Lan QS, et al. Knockdown of linc-POU3F3 suppresses the proliferation, apoptosis, and migration resistance of colorectal cancer. Oncotarget. 2016: 7(1):961-75.

157. Li J, Wang J, Zhong Y, Guo R, Chu D, Qiu H, Yuan Z. HOTAIR: a key regulator in gynecologic cancers. Cancer Cell Int. 2017;17:65.

158. Miao Z, Ding J, Chen B, Yang Y, Chen Y. HOTAIR overexpression correlated with worse survival in patients with solid tumors. Minerva Med. 2016; 107(6):392-400.

159. Qin J, Ning H, Zhou Y, Hu Y, Yang L, Huang R. LncRNA MIR31HG overexpression serves as poor prognostic biomarker and promotes cells proliferation in lung adenocarcinoma. Biomed Pharmacother. 2018;99:363-8.

160. He A, Chen Z, Mei H, Liu Y. Decreased expression of LncRNA MIR31HG in human bladder cancer. Cancer Biomark. 2016;17(2):231-6.

161. Shi WH, Wu QQ, Li SQ, Yang TX, Liu ZH, Tong YS, Tuo L, Wang S, Cao XF. Upregulation of the long noncoding RNA PCAT-1 correlates with advanced clinical stage and poor prognosis in esophageal squamous carcinoma. Tumour Biol. 2015;36(4):2501-7.

162. Ke S, Li RC, Meng FK, Fang MH. NKILA inhibits NF-kappaB signaling and suppresses tumor metastasis. Aging (Albany NY). 2018;10(1):56-71.

163. Xie HW, Wu QQ, Zhu B, Chen FJ, Ji L, Li SQ, Wang CM, Tong YS, Tuo L, Wu $M$, et al. Long noncoding RNA SPRY4-IT1 is upregulated in esophageal squamous cell carcinoma and associated with poor prognosis. Tumour Biol. 2014;35(8):7743-54.

164. Shi H, Liu Z, Pei D, Jiang Y, Zhu H, Chen B. Development and validation of nomogram based on IncRNA ZFAS1 for predicting survival in lymph nodenegative esophageal squamous cell carcinoma patients. Oncotarget. 2017; 8(35):59048-57.

Ready to submit your research? Choose BMC and benefit from:

- fast, convenient online submission

- thorough peer review by experienced researchers in your field

- rapid publication on acceptance

- support for research data, including large and complex data types

- gold Open Access which fosters wider collaboration and increased citations

- maximum visibility for your research: over $100 \mathrm{M}$ website views per year

At $\mathrm{BMC}$, research is always in progress.

Learn more biomedcentral.com/submissions 